\title{
Variation in brooding period masks similarities in response to changing temperatures
}

\author{
Erica L. Westerman ${ }^{1, *}$, Robert Whitlatch ${ }^{2}$, Jennifer A. Dijkstra $^{3}$, Larry G. Harris ${ }^{3}$ \\ ${ }^{1}$ Ecology and Evolutionary Biology Department, 165 Prospect Street, Yale University, New Haven, Connecticut 06511, USA \\ ${ }^{2}$ Department of Marine Sciences, 1080 Shennecossett Road, University of Connecticut, Groton, Connecticut 06340, USA \\ ${ }^{3}$ Zoology Department, 46 College Road, University of New Hampshire, Durham, New Hampshire 03824, USA
}

\begin{abstract}
Increased awareness of climate change and invasive species has resulted in a surge of studies on how climate change impacts the invasibility of communities. A common method of study is comparing temperature ranges of native or naturalized species to those of highly invasive species. Two fouling community animals that have been so compared are the ascidians Botryllus schlosseri and Botrylloides violaceus. However, temperature range comparisons of different life history traits yield conflicting results. We examined the 2 species to identify a characteristic that could explain these discrepancies and found a single outstanding feature: the brooding period in B. violaceus is at least 5 times that of $B$. schlosseri. To determine if this elongated brooding period accounted for the observed discrepancies in temperature range, the relationship between recruitment and temperature was reanalyzed using estimated fertilization times for 2001-2006 recruitment at the Groton Long Point Marina and the University of Connecticut, Avery Point, and 2006 recruitment at the University of Maine Darling Marine Center. Estimated fertilization occurred at the same water temperatures for $B$. violaceus and B. schlosseri colonies. The observed delay in initial recruitment of B. violaceus resulted from the elongated brooding period, not a delay in fertilization due to water temperature. Analyzing recruitment data without incorporating brooding period may not be representative of reproductive environmental requirements and ranges for animals with brooding periods, and may result in uninformative conclusions when comparing species whose brooding periods differ significantly.
\end{abstract}

KEY WORDS: Invasive species · Recruitment $\cdot$ Abiotic factors $\cdot$ Ascidians

\section{INTRODUCTION}

Two of the most dramatic and anthropogenically influenced forces acting on ecological communities today are increasing prevalence of non-native species and climate change. As both can alter species interactions in all environments, there is currently a great deal of interest in the existence of synergistic effects between non-native species establishment and climate change, particularly in temperate regions of the world (Simberloff 2000, Mooney \& Cleland 2001, Stachowicz et al. 2002, Harley et al. 2006).

The most common method used to examine the interactions between climate change and native and non-native species is to compare their relative fitness under expected climate change conditions. Initially used to examine terrestrial plant communities (Dukes \& Mooney 1999), this method has been applied to marine systems, most notably coastal sessile benthic communities in New England (Stachowicz et al. 2002). Results from both terrestrial and marine studies suggest that elevated temperatures result in increased fitness of non-native compared to native species (Dukes \& Mooney 1999, Stachowicz et al. 2002). As space and access to nutrients are limiting in both terrestrial plant and sessile benthic communities, using similar methods to examine the impacts of climate change and nonnative species on these 2 systems seems reasonable. 
However, while many of the species chosen to examine this relationship in terrestrial systems are known to have similar life histories, the complete life histories of species in sessile benthic communities are not as well understood (Eckman 1996). This is potentially a problem as species in these communities may be viviparous brooders or broadcast spawners, species with many juvenile stages or direct development (Dijkstra et al. $2007 \mathrm{~b}$ ). The diversity of life histories adds to the complexity of conclusively assessing how climate change may impact the fitness of both native and non-native species. For this reason, one should proceed with caution when comparing fitness responses to environmental conditions in sessile benthic species with relatively unknown life histories.

For example, closer examination of the life history characteristics of 2 species of colonial ascidians investigated by Stachowicz et al. (2002), Botryllus schlosseri (a naturalized species) and Botrylloides violaceus (a non-native species), offers an explanation of their results other than a difference in reproductive temperature tolerances. Stachowicz et al. (2002) found that Julian date of initial recruitment was negatively correlated with winter water temperature for $B$. violaceus but not B. schlosseri. These results imply that $B$. violaceus tolerates higher water temperatures than $B$. schlosseri, and will therefore have a competitive advantage over B. schlosseri as water temperatures continue to increase due to climate change (Stachowicz et al. 2002). However, temperature-induced reaction norms of growth, time required to undergo asexual reproduction and production of viable offspring in these 2 species are comparable in both native and nonnative habitats (Brunetti et al. 1980, 1984, Saito et al. 1981, Boyd et al. 1986, McCarthy et al. 2007). Also, both species have comparable latitudinal distributions in North America and in their native waters (Millar 1971, Saito et al. 1981, Dijkstra et al. 2007a). Stachowicz et al. (2002) did show that $B$. violaceus grew faster than B. schlosseri at warmer temperatures in a 1-wk study, while McCarthy et al. (2007) showed no difference in growth rates during a similarly timed study.

The comparable temperature ranges of Botrylloides violaceus and Botryllus schlosseri suggest that they are both temperate species, while the correlation of date of initial recruitment with temperature for $B$. violaceus in Connecticut (Stachowicz et al. 2002) suggests B. violaceus is nearer the edge of its temperature range than B. schlosseri. Since recruitment is the only documented temperature-dependent life history trait that differs between these 2 species, and since the 2 species have been used as an example of how climate change may be facilitating the success of invasive species in benthic marine communities (Stachowicz et al. 2002), the temperature-driven difference in recruitment deserves greater examination. It is possible that B. schlosseri reproduces at cooler temperatures than the invasive species $B$. violaceus, while all other life history traits in the 2 species exhibit similar temperature-induced reaction norms. However, subtle differences in the life histories of the 2 species may result in an incomplete story when comparing the influence of temperature on recruitment.

Botryllus schlosseri and Botrylloides violaceus, like all colonial ascidians, have internal fertilization and release competent larvae into the water column after a brooding period (Berrill 1950, Millar 1971). Larvae remain in the water column for $<24 \mathrm{~h}$ before settling on hard substrate, metamorphosing and growing into adult colonies (Millar 1971). While recruitment studies of sessile invertebrates document the timing of settlement, they do not incorporate the duration of the brooding period into calculations of temperaturerelated effects on reproductive processes (StanwellSmith \& Barnes 1997, Whitlatch \& Osman 1998, Stachowicz et al. 2002, Watson \& Barnes 2004, Agius 2007 , Tyrrell \& Byers 2007). As different species of colonial ascidians are known to have brooding periods of varying lengths (Van Name 1945, Saito \& Okuyama 2003), we hypothesize that the differing recruitment temperature ranges of $B$. schlosseri and $B$. violaceus may be an artifact of different brooding periods between species with similar reproductive temperature ranges, and not the result of different reproductive temperature ranges. We tested this hypothesis by using a model that incorporates brooding period and recruitment temperature data to determine water temperatures at estimated dates of initial fertilization for both species of ascidians.

\section{MATERIALS AND METHODS}

Study organisms. Botryllus schlosseri and Botrylloides violaceus are colonial ascidians belonging to the subfamily Botryllidae (Phylum Chordata, Subphylum Tunicata, Class Ascidiacea, Order Stolidobranchia, Family Styelidae). B. schlosseri has been a member of the Gulf of Maine subtidal community since the mid1800 s and was the historically dominant colonial tunicate in the Gulf of Maine until the late 1980s (Gould 1870, Harris \& Tyrrell 2001). B. violaceus arrived in the Gulf of Maine in the early 1980s and has since become a dominant member of the benthic community (Berman et al. 1992).

Botryllus schlosseri and Botrylloides violaceus undergo regular cycles of complete zooid replacement (blastogenic cycle). The duration of the blastogenic cycle is correlated with temperature, and has been well documented for many botryllid ascidians, includ- 
ing B. schlosseri, Botrylloides simodensis and Botrylloides leachi, but not for B. violaceus (Yamaguchi 1975, Brunetti et al. 1980, Grosberg 1988). The brooding period of the oocytes within a colony lasts for the duration of different numbers of blastogenic cycles, with the number of blastogenic cycles being species-specific. Oocytes are fertilized at the beginning of a blastogenic cycle and larvae released at the end of the same cycle for B. schlosseri (Yund et al. 1997, StewartSavage et al. 2001), while larvae are released at the end of either the 6th or 7th blastogenic cycle after fertilization for B. violaceus (Saito et al. 1981).

Botrylloides violaceus blastogenic cycle duration. In order to determine whether the duration of the Botrylloides violaceus blastogenic cycle was correlated with temperature in a similar fashion as that of Botryllus schlosseri, non-reproductive colonies of $B$. violaceus (1 to 60 zooids) were collected from the Darling Marine Center (DMC), Maine, in July 2006, brought into the laboratory and allowed to adhere to glass slides. B. schlosseri colonies were also collected to insure that the relationship of duration of blastogenic cycle and temperature for ascidians at DMC did not differ from that previously reported for ascidians collected from more southern sites. After settlement, colonies were hung vertically in a tank with low flow until they attached to the microscope slide (see Phillippi et al. 2004 for details) and then placed in one of 4 temperature treatments. In order to rule out a container effect, there were 3 tanks per temperature treatment, and colonies were maintained in either $18.9 \mathrm{l}$ tanks or 15.14 l plastic tubs containing 9.5 to $10.5 \mathrm{l}$ of 32 psu seawater. A minimum of 3 colonies of each species were initially placed in each tank. Due to survival rates during the 2-wk acclimatization period, the number of colonies in each treatment varied from 5 for both B. schlosseri and B. violaceus at $15^{\circ} \mathrm{C}$ to 12 for B. violaceus at $10^{\circ} \mathrm{C}$. Water was changed weekly. Animals were fed Coralife ${ }^{\circledR}$ Invertebrate Smogasbord ${ }^{\mathrm{TM}}$ daily (5 drops a day for the first 5 colonies, and an extra drop for every colony containing $>50$ zooids) and were in constant light. Colonies were placed in 4 different temperature controlled rooms $\left(5,10,15\right.$ and $\left.20^{\circ} \mathrm{C}\right)$. After a 2-wk acclimatization period, colonies were monitored daily and the duration of 1 blastogenic cycle for each colony at each temperature was recorded. Mean duration of blastogenic cycle was compared between species for each temperature and between containers for each treatment using a Student's $t$-test.

Field sites. Ascidian recruitment data were collected from 3 different sites over 6 yr: DMC and Avery Point (AP) in Maine, and Groton Long Point (GLP) in Connecticut. Recruitment data from Connecticut were collected from 2001 to 2006, while data from Maine were collected only in 2006.
DMC on the Damariscotta River $\left(43^{\circ} 56.0^{\prime} \mathrm{N}\right.$, $69^{\circ} 34.8^{\prime} \mathrm{W}$ ) has a yearly water temperature range of $\sim 0.7$ to $\sim 20.51^{\circ} \mathrm{C}$ with an average of $9.89^{\circ} \mathrm{C}$ (Westerman 2007). AP $\left(41^{\circ} 18.89^{\prime} \mathrm{N}, 72^{\circ} 3.65^{\prime} \mathrm{W}\right)$ and GLP $\left(41^{\circ} 18.75^{\prime} \mathrm{N}, 72^{\circ} 0.65^{\prime} \mathrm{W}\right)$ experience a yearly seawater temperature range of $\sim 2.0$ to $\sim 25.5^{\circ} \mathrm{C}$ (Stachowicz et al. 2002). Panels at all 3 sites were hung from floating docks with the panels positioned face-down $\sim 1 \mathrm{~m}$ below the water surface. AP and GLP are located in areas of a moderate amount of residential development, while DMC is located in an area with little residential development.

Recruitment data. Recruitment data at DMC were collected by deploying six $100 \mathrm{~cm}^{2}$ Plexiglas ${ }^{\circledR}$ recruitment panels beginning in May 2006. Panels were replaced and taken back to the laboratory every $2 \mathrm{wk}$ and examined under a dissecting microscope; the number of Botrylloides violaceus and Botryllus schlosseri recruits per panel were recorded. Data were collected from May to December 2006. Recruitment data at AP and GLP were collected using four $100 \mathrm{~cm}^{2}$ PVC panels deployed in April 2001 at AP and April 2002 at GLP. Panels were replaced and taken back to the laboratory on a weekly basis and examined under a dissecting microscope. The number of $B$. violaceus and B. schlosseri recruits per panel were recorded. Panels were deployed from April to November through 2006.

Ascidian recruitment was defined as those juveniles that settled during the 1- or 2-wk panel deployment periods. Initial recruitment was defined as the date of the first recruit observed on the collected panel for the year. If the date of the first recruit observed on the collection panel was the same as the date of first observation of the panel, the data point for that panel was excluded. $\mathrm{HOBO}^{\mathrm{TM}}$ temperature loggers recording water temperature every $2 \mathrm{~h}$ were deployed at the depth of the panels at all sites for the duration of the recruitment studies and were used to obtain water temperatures of date of initial recruitment.

Initial fertilization temperature model. The date of initial recruitment $(I)$ was defined as a function of time of fertilization $(F)$ and duration of brooding period $(B)$ :

$$
I=F+B
$$

The duration of brooding period for B. schlosseri and $B$. violaceus was defined as a function of the number (b) and length of blastogenic cycles (l):

$$
B=b l
$$

The length of blastogenic cycle is dependent on ambient average seawater temperature $(T)$ and, therefore, changes throughout the year $(l=185.99 / T-2.1876$ for B. schlosseri, equation based on data from Grosberg 1982). While the number of blastogenic cycles is 
variable between species, it is constant within species, so the only factor responsible for within-species brooding period variation is the length of the blastogenic cycle at the average seawater temperature. Therefore, the date of initial recruitment is a function of initial time of fertilization, seawater temperature and number of blastogenic cycles required for the development of an embryo:

$$
I=F+b l
$$

By rearranging Eq. (3), the date of initial fertilization can be calculated using $F=I-b l$. However, since the length of blastogenic cycle varies with seawater temperature and temperature changes seasonally at the study sites, a more accurate calculation of time of fertilization can be obtained by summing the series of the length of the blastogenic cycle at the average seawater temperature, which yields:

$$
F=I-\sum_{\mathrm{n}=1}^{\mathrm{b}} 1_{\mathrm{n}}
$$

where $n$ is length of total brooding period.

The method for estimating time of initial fertilization is highly dependent on the length of blastogenic cycle. Since the relationship between blastogenic cycle length and temperature is well established for Botryllus schlosseri (Brunetti et al. 1980, Grosberg 1982, Mukai et al. 1987, Saito \& Okuyama 2003) and we found no significant difference between duration of blastogenic cycle in B. schlosseri and Botrylloides violaceus at the temperatures tested (Student's $t$-test, $5^{\circ} \mathrm{C}$ : $\mathrm{df}=4.6, \mathrm{p}=0.80 ; 10^{\circ} \mathrm{C}: \mathrm{df}=11.7, \mathrm{p}=0.50 ; 15^{\circ} \mathrm{C}: \mathrm{df}=$ $3.6, p=0.12 ; 20^{\circ} \mathrm{C}: \mathrm{df}=7.7, \mathrm{p}=0.65 ;$ no container effect), the equation used to compute duration of blastogenic cycle from sea surface temperature in the model was the same for both species: $l=185.99 / T-$ 2.1876. This equation can be substituted for the length of blastogenic cycle (l), making initial fertilization a function of initial recruitment and temperature $(T)$ :

$$
F=I-\sum_{\mathrm{n}=1}^{\mathrm{b}} 185.99 / T_{\mathrm{n}}-2.1876
$$

Once the date of initial fertilization was calculated, the water temperature was obtained by averaging the 84-measurement temperature record for the $7 \mathrm{~d}$ prior to (and including) the estimated date of initial fertilization. Estimated temperature of initial fertilization and temperature of initial recruitment were compared between species using the pooled data from the first appearance of a recruit on a panel at each site each year by a 1-way ANOVA. Estimated temperatures of initial fertilization and initial appearance on panel were then compared between species by site and by year using the initial appearance on panel data for all panels at all sites via 1-way ANOVAs. Only years and sites with initial recruitment data and temperature data for both recruitment and fertilization were used. This resulted in the exclusion of AP recruitment data from 2001 to 2005, and of GLP recruitment data from 2005. All statistical analyses were conducted using $\mathrm{JMP}^{\circledR}$ version 7 .

\section{RESULTS}

Botryllus schlosseri initial recruitment occurred at cooler water temperatures than Botrylloides violaceus at all sites and years (Table 1). Recruitment ended at the same time for both species across sites and years, and duration of blastogenic cycle did not differ between species at the temperatures tested (results presented in text describing Eq. 5). When data were pooled, B. schlosseri initial recruitment occurred at water temperatures 4 degrees cooler on average than that of $B$. violaceus $\left(11.7\right.$ vs. $\left.15.6^{\circ} \mathrm{C} ; \mathrm{p}=0.0053, \mathrm{df}=14\right)$. However, estimated initial fertilization temperature was the same for both species $\left(10^{\circ} \mathrm{C}\right)$ with no variation between sites $(p=0.76, d f=14)$. Results did not change with the removal of DMC data; suggesting the 2-fold difference in temporal resolution of recruitment data collection between DMC and the 2 other sites (AP and GLP) did not influence our results. Estimated initial fertilization temperature for both species remained at $10^{\circ} \mathrm{C}(\mathrm{p}=0.627, \mathrm{df}=13)$, while initial recruitment temperatures for the 2 species remained significantly different from each other $\left(11.7^{\circ} \mathrm{C}\right.$ compared to $\left.15.6^{\circ} \mathrm{C}\right)$ $(p=0.0098, d f=12)$.

When data from each panel at each site were included and comparisons of occurrence on panel and estimated fertilization temperatures were separated by site and year, there were 2 instances in which results differed from that of the pooled data. Botrylloides violaceus initial fertilization occurred at a cooler temperature than that of Botryllus schlosseri in 2004 ( $\mathrm{p}=$ 0.0467), and B. schlosseri initial fertilization occurred at a cooler temperature than that of $B$. violaceus in 2002 ( $p=0.0012$ ) (Table 1). Although initial fertilization of $B$. schlosseri was at a cooler temperature than that of B. violaceus, it occurred later in the year (Fig. 1). Water temperatures dropped at the end of April between the time of $B$. violaceus fertilization and that of B. schlosseri.

The similar estimated fertilization temperatures calculated using the observed recruitment data and the fertilization time model demonstrate that the observed delay in Botrylloides violaceus recruitment relative to Botryllus schlosseri recruitment can be explained solely by the difference in duration of brooding period for these 2 species. 
Table 1. Botryllus schlosseri and Botrylloides violaceus. Initial recruitment and estimated initial fertilization temperatures (SE) by site and year. DMC: Darling Marine Center, Maine; AP: Avery Point, Maine; GLP: Groton Long Point, Connecticut

\begin{tabular}{|c|c|c|c|c|c|c|c|}
\hline & \multicolumn{3}{|c|}{ Initial recruitment temperature $\left({ }^{\circ} \mathrm{C}\right)$} & \multicolumn{3}{|c|}{ Initial fertilization temperature $\left({ }^{\circ} \mathrm{C}\right)$} & \multirow[b]{2}{*}{$\mathrm{df}$} \\
\hline & B. schlosseri & B. violaceus & $p$ & B. schlosseri & B. violaceus & $p$ & \\
\hline \multicolumn{8}{|l|}{ Site } \\
\hline DMC & $14.97(0.47)$ & 16.3(0.36) & 0.05 & $12.89(0.40)$ & $11.21(0.76)$ & 0.067 & 11 \\
\hline $\mathrm{AP}$ & $11.84(0.73)$ & $15.82(0.22)$ & $0.0001^{*}$ & $10.57(0.83)$ & $10.87(0.56)$ & 0.72 & 21 \\
\hline GLP & $12.68(0.09)$ & $15.67(0.09)$ & $<0.0001^{*}$ & $10.75(0.17)$ & $10.99(0.35)$ & 0.55 & 27 \\
\hline \multicolumn{8}{|l|}{ Year } \\
\hline 2002 & $12.76(0.31)$ & $15.01(0.26)$ & $0.0008^{*}$ & $9.94(0.00)$ & 11.94(0.49) & $0.0012^{*}$ & 11 \\
\hline 2003 & $11.85(0.29)$ & $16.09((.07)$ & $<0.0001^{*}$ & $10.82(0.32)$ & $10.42(0.25)$ & 0.8 & 23 \\
\hline 2004 & $12.59(0.52)$ & $15.51(0.20)$ & $0.0006^{*}$ & $12.07(0.70)$ & $10.75(0.09)$ & $0.047^{*}$ & 13 \\
\hline 2006 & $14.97(0.47)$ & $16.3(0.36)$ & 0.05 & $12.89(0.40)$ & $11.21(0.76)$ & 0.067 & 11 \\
\hline
\end{tabular}

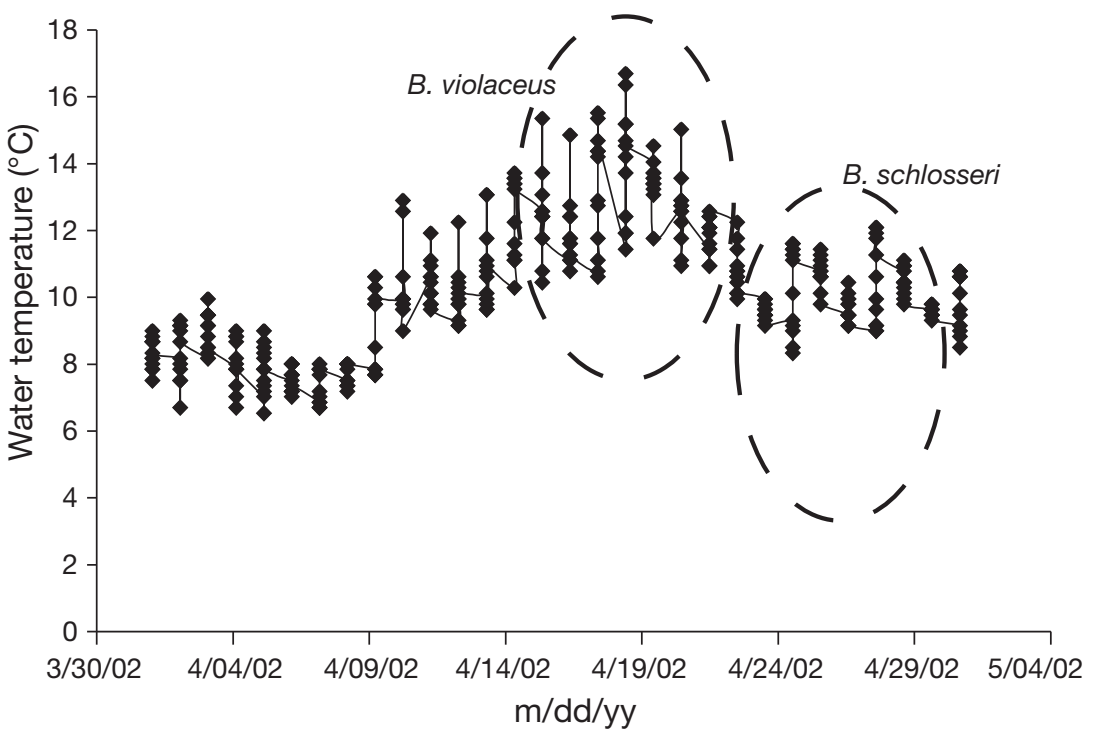

Fig. 1. Botrylloides violaceus and Botryllus schlosseri. Average water temperature at Avery Point and Groton Long Point for April 2002. Dashed ovals indicate date of estimated initial fertilization for $B$. violaceus and B. schlosseri

crepancy in classification of Botrylloides violaceus temperature ranges relative to those of Botryllus schlosseri. The variation in the correlations between temperature and recruitment found in both the present study (Table 1) and Stachowicz et al. (2002) can be better explained by the variation in the number of blastogenic cycles (5 versus 1, Saito et al. 1981, Yund et al. 1997) required for producing a competent larva in the 2 species than by the 2 species having differing temperature-induced reaction norms.

While the linear equation describing the relationship between duration of blastogenic cycle and temperature in the model was the same for the 2 species compared in the present study, this relationship is likely

\section{DISCUSSION}

Many benthic community studies describe correlations between species recruitment rates and environmental factors such as water temperature and phytoplankton blooms (Robles 1997, Stanwell-Smith \& Barnes 1997, Whitlatch \& Osman 1998, Miller et al. 2000, Watson \& Barnes 2004). While these studies provide useful information, they often fail to take into account between-species variability in brooding periods, and may therefore miss important interactions between environmental factors and developmental processes (Roughgarden et al. 1988, Eckman 1996). The failure to incorporate brooding period can be particularly detrimental when trying to draw conclusions about environmental effects on reproduction based on recruitment data for 2 species with very different brooding periods. This is likely the cause of the dis- to be species- and possibly population-specific, and should be empirically determined prior to model use. If found to differ for other brooding ascidians or other populations of Botryllus schlosseri and Botrylloides violaceus, the linear equation describing the relationship between blastogenic cycle duration and temperature can be replaced and the initial fertilization temperature calculated with a species-specific temperature/blastogenic cycle linear equation.

When brooding period is incorporated into the explanation of recruitment temperature range, Botryllus schlosseri can no longer be considered a more reproductively cold-tolerant species than Botrylloides violaceus (Table 1). This result corroborates the laboratory and field reproductive temperature range of $B$. violaceus in Japan (Saito et al. 1981) and those of $B$. schlosseri in Italy and the United States (Brunetti et al. 1984, Chadwick-Furman \& Weissman 1995). Both spe- 
cies have similar reproductive, blastogenic cycle and geographic temperature ranges. The greater abundance of $B$. violaceus relative to $B$. schlosseri in benthic communities where they coexist may be better explained by the ability of $B$. violaceus to overgrow $B$. schlosseri (Grosberg 1988) and to produce larger larvae more likely to survive post-settlement (Pechenik 1999; 3.0 mm, Mukai et al. 1987, vs. 1.5 mm, Grave \& Woodbridge 1924) than by any difference in species temperature ranges.

While embryonic brooding period data are not be available for all brooding species, it should be incorporated into the analysis of recruitment data when possible, as it may represent a significant portion of both the parent and the offspring's lifespan and can be highly variable between species. For example, a Botrylloides violaceus colony may spend over half its lifespan brooding one set of embryos, while a Botryllus schlosseri colony may spend less than a quarter of its lifespan brooding a set of embryos. Also, B. violaceus colonies are truly viviparous, with blood from multiple asexual generations within the colony entering the egg during the long brooding period, while B. schlosseri are oviviparous (Mukai et al. 1987). This may result in high interspecies variation in reproductive sensitivity to changes in environmental conditions, as energy input and period of developmental vulnerability shift with duration of brooding period.

The vast difference in the time and energy required to produce a larva capable of settling on a recruitment plate for these 2 species highlights one of the flaws in using recruitment as the sole measurement of environmental impact on reproduction. While recruitment data are useful for addressing a variety of questions (including but not limited to determining seasonal abundance patterns, quantities of juveniles entering a community and health of a population) and for allowing one to make comparisons between species with different life histories, environmental factors such as temperature are often not acting on recruitment per se, but on the reproductive and developmental processes such as fertilization, brooding period, larval release and metamorphosis that result in the observed recruitment. The importance of this distinction has been acknowledged and incorporated into studies examining animals with long-term planktonic larvae, such as lobsters (MacKenzie 1988, Lee et al. 1992, Tong et al. 2000), but has not yet been incorporated into studies of animals with short-term planktonic larvae and potentially long-term brooding periods, such as ascidians. Ascidians are increasingly becoming dominant members of sessile benthic communities and are prominent invasive species on a global scale. Given ascidian reproductive life history variation, the inclusion of reproductive life history characteristics other than recruitment into our models of benthic community response to climate change seems paramount. Further research examining how environmental change influences brooding periods as well as pelagic larval forms will allow for new analyses of previously obtained recruitment data, resulting in an enhanced understanding of the dynamics of the sessile benthic community.

Acknowledgements. We thank R. Story, M. Westerman and A. Dunn for assistance with recruitment data collection. We acknowledge funding to E.L.W. by a National Estuarine Research Reserve Graduate Student Fellowship and a research grant from the University of New Hampshire Marine Program, as well as a New Hampshire Estuarine Projects Grant for E.L.W., J.A.D. and L.G.H. R.W. was funded by National Science Foundation and US Environmental Protection Agency for collection of recruitment data at the Connecticut field sites.

\section{LITERATURE CITED}

Agius BP (2007) Spatial and temporal effects of pre-seeding plates with invasive ascidians: growth, recruitment and community composition. J Exp Mar Biol Ecol 342:30-39

Berman J, Harris L, Lambert W, Buttrick M, Dufresne M (1992) Recent invasions of the Gulf of Maine: three contrasting ecological histories. Conserv Biol 6:435-441

Berrill NJ (1950) The Tunicata. Ray Society of London, London

Boyd HC, Brown SK, Harp JA, Weissman IL (1986) Growth and sexual maturation of laboratory-cultured Monterey Botryllus schlosseri. Biol Bull 170:91-109

Brunetti R, Beghi L, Bressan M, Marin MG (1980) Combined effects of temperature and salinity on colonies of Botryllus schlosseri and Botrylloides leachi (Ascidiacea) from the Venetian Lagoon. Mar Ecol Prog Ser 2:303-314

Brunetti R, Marin MG, Bressan M (1984) Combined effects of temperature and salinity on sexual reproduction and colonial growth of Botryllus schlosseri (Tunicata). Boll Zool 51:405-411

Chadwick-Furman NE, Weissman IL (1995) Life histories and senescence of Botryllus schlosseri (Chordata, Ascidiacea) in Monterey Bay. Biol Bull 189:36-41

> Dijkstra J, Harris L, Westerman E (2007a) Distribution and long-term temporal patterns of four invasive colonial ascidians in the Gulf of Maine. J Exp Mar Biol Ecol 342:61-68

> Dijkstra J, Sherman H, Harris LG (2007b) The role of colonial ascidians in altering biodiversity in marine fouling communities. J Exp Mar Biol Ecol 342:169-171

Dukes JS, Mooney HA (1999) Does global change increase the success of biological invaders? Trends Ecol Evol 14: $135-139$

Eckman JE (1996) Closing the larval loop: linking larval ecology to the population dynamics of marine benthic invertebrates. J Exp Mar Biol Ecol 200:207-237

Gould AA (1870) Report on the Invertebrata of Massachusetts. Wright \& Potter, State Printers, Boston, MA

> Grave C, Woodbridge H (1924) Botryllus schlosseri (Pallas): the behavior and morphology of the free-swimming larva. J Morphol 39:207-247

Grosberg R (1982) Ecological, genetical and developmental factors regulating life history variation within a population of the colonial ascidian Botryllus schlosseri (Pallas) Savigny. PhD dissertation, Yale University, New Haven, CT 
Grosberg RK (1988) Life history variation within a population of the colonial ascidian Botryllus schlosseri. I. The genetic and environmental control of seasonal variation. Evolution 42:900-920

Harley CDG, Hughes AR, Hultgren KM, Miner BG and others (2006) The impacts of climate change in coastal marine systems. Ecol Lett 9:228-241

Harris LG, Tyrrell MC (2001) Changing community states in the Gulf of Maine: synergism between invaders, overfishing and climate change. Biol Invasions 3:9-21

Lee TN, Rooth C, Williams E, McGowan M, Szmant AF (1992) Influence of Florida current, gyres and wind-driven circulation on transport of larvae and recruitment in the Florida Keys coral reefs. Cont Shelf Res 12:971-1002

MacKenzie BR (1988) Assessment of temperature effects on interrelationships between stage durations, mortality, and growth in laboratory-reared Homarus americanus Milne Edwards larvae. J Exp Mar Biol Ecol 116:87-98

McCarthy A, Osman RW, Whitlatch RB (2007) Effects of temperature on growth rates of colonial ascidians: a comparison of Didemnum sp. to Botryllus schlosseri and Botrylloides violaceus. J Exp Mar Biol Ecol 342:172-174

- Millar RH (1971) The biology of ascidians. Adv Mar Biol 9: $1-100$

Miller MW, Weil E, Szmant AM (2000) Coral recruitment and juvenile mortality as structuring factors for reef benthic communities in Biscayne National Park, USA. Coral Reefs 19:115-123

Mooney HA, Cleland EE (2001) The evolutionary impact of invasive species. Proc Natl Acad Sci USA 98:5446-5451

Mukai H, Saito Y, Watanabe H (1987) Viviparous development in Botrylloides (compound ascidians). J Morphol 193: 263-276

Pechenik JA (1999) On the advantages and disadvantages of larval stages on benthic marine invertebrate life cycles. Mar Ecol Prog Ser 177:269-297

Phillippi A, Hamann E, Yund PO (2004) Fertilization in an egg-brooding colonial ascidian does not vary with population density. Biol Bull 206:152-160

Robles CD (1997) Changing recruitment in constant species assemblages: implications for predation theory in intertidal communities. Ecology 78:1400-1414

Roughgarden J, Gaines SD, Possingham H (1988) Recruitment dynamics in complex life cycles. Science 241:1460-1466

Saito Y, Okuyama M (2003) Studies on Japanese botryllid ascidians. IV. A new species of the genus Botryllus with a unique colony shape, from the vicinity of Shimoda. Zool Sci 20:1153-1161

Editorial responsibility: Otto Kinne, Oldendorf/Luhe, Germany
Saito Y, Mukai H, Watanabe H (1981) Studies on Japanese compound styelid ascidians. II. A new species of the genus Botrylloides and redescription of $B$. violaceus Oka. Publ Seto Mar Biol Lab 26:357-368

Simberloff D (2000) Global climate change and introduced species in United States forests. Sci Total Environ 262: 253-261

Stachowicz JJ, Terwin JR, Whitlatch RB, Osman RW (2002) Linking climate change and biological invasions: ocean warming facilitates nonindigenous species invasions. Proc Natl Acad Sci USA 99:15497-15500

Stanwell-Smith D, Barnes DKA (1997) Benthic community development in Antarctica: recruitment and growth on settlement panels at Signy Island. J Exp Mar Biol Ecol 212: $61-79$

Stewart-Savage J, Phillippi A, Yund PO (2001) Delayed insemination results in embryo mortality in a brooding ascidian. Biol Bull 201:52-58

Tong LJ, Moss GA, Pickering TD, Paewai MP (2000) Temperature effects on embryo and early larval development of the spiny lobster Jasus edwardsii, and description of a method to predict larval hatch times. Mar Freshw Res 51: $243-248$

Tyrrell MC, Byers JE (2007) Do artificial substrates favor nonindigenous fouling species over native species? J Exp Mar Biol Ecol 342:54-60

Van Name WG (1945) The North and South American ascidians. Bull Am Mus Nat Hist 84:1-476

Watson DI, Barnes DKA (2004) Temporal and spatial components of variability in benthic recruitment, a 5-year temperate example. Mar Biol 145:201-214

Westerman E (2007) Impacts of changing water temperature on the life histories of two invasive ascidians in the Gulf of Maine: Botryllus schlosseri and Botrylloides violaceus. MS dissertation, University of New Hampshire, Durham

Whitlatch RB, Osman RW (1998) A new device for studying benthic invertebrate recruitment. Limnol Oceanogr 43: 516-523

Yamaguchi M (1975) Growth and reproductive cycles of the marine fouling ascidians Ciona intestinalis, Styela plicata, Botrylloides violaceus, and Leptoclinum mitsukurii at Aburatsubo-Moroiso Inlet (Central Japan). Mar Biol 29: 253-259

> Yund PO, Marcum Y, Stewart-Savage J (1997) Life-history variation in a colonial ascidian: broad-sense heritabilities and tradeoffs in allocation to asexual growth and male and female reproduction. Biol Bull 192:290-299

Submitted: June 17, 2008; Accepted: May 8, 2009

Proofs received from author(s): September 18, 2009 